\title{
Transcription of the 5S rRNA heterochromatic genes is epigenetically controlled in Arabidopsis thaliana and Xenopus laevis
}

\author{
J Douet and S Tourmente \\ Unité Mixte de Recherche CNRS 6547 BIOMOVE, Université Blaise Pascal, Aubière Cedex, France
}

$5 S$ ribosomal DNA is a highly conserved tandemly repeated multigenic family. As suggested for a long time, we have shown that only a fraction of the 5S rRNA genes are expressed in Arabidopsis thaliana. In Xenopus laevis, there is a developmental control of the expression of the $5 \mathrm{~S}$ rRNA genes with only one of the two 5S rDNA families expressed during oogenesis. For both Arabidopsis and Xenopus, the strongest transcription of $5 S$ rRNA, respectively in the seed and during oogenesis is correlated with heterogeneity in the transcribed 5S rRNAs. Epigenetic mechanisms such as modification of the chromatin structure are involved in the transcriptional regulation of the 5S rRNA genes in both organisms. In Arabidopsis, two silencing pathways, methylation-dependent (RNAi) and methylationindependent (MOM pathway), are involved in the silencing of a 5 S rDNA fraction.

Heredity (2007) 99, 5-13; doi:10.1038/sj.hdy.6800964; published online 9 May 2007

Keywords: 5S rDNA; epigenetic; transcription; Arabidopsis thaliana; Xenopus laevis

\section{Introduction}

Higher eukaryotes contain thousands of rRNA genes, and it has been believed for some time that only a fraction of rRNA genes are active, since the number of these genes far exceeds that expected to be required to supply ample cytoplasmic rRNA (reviewed in Rogers and Bendich, 1987).

Eukaryotes regulate the effective dosage of their $45 \mathrm{~S}$ rRNA genes with fewer than half of the genes being transcribed by polymerase I at any one time. rRNA gene dosage control utilizes a common mechanism with nuclear dominance, a phenomenon in which genetic hybrids transcribe the rRNA genes inherited from one parent, whereas the rRNA genes of the other parent are inactive (Pikaard, 2000). Central to this mechanism is an epigenetic switch in which concerted changes in promoter cytosine methylation density and specific histone modifications dictate the on and off states of rRNA genes (Lawrence et al., 2004).

In most eukaryotes, the 5S rRNA genes are organized as separate clusters of tandem repeats transcribed by RNA polymerase III. There is a substantial literature on $5 S$ rDNA but most reports concern the size of the repeat, its copy number and chromosomal localization obtained from in situ hybridizations. In the yeast model, considerable work concerns the characterization of polymerase III transcription machinery components (Geiduschek and Kassavetis, 2001; Ducrot et al., 2006). The first results on

Correspondence: Dr S Tourmente, Unité Mixte de Recherche CNRS 6547 BIOMOVE, Université Blaise Pascal, 24 Avenue des Landais, 63177 Aubière Cedex, France.

E-mail: sylvette.tourmente@univ-bpclermont.fr

Received 6 December 2006; revised 13 February 2007; accepted 16 February 2007; published online 9 May 2007 the regulation of $5 \mathrm{~S}$ rDNA transcription were obtained in Xenopus laevis, where a developmental control of the $5 S$ rRNA genes expression occurs. The somatic gene family (400 copies organized in tandem) is expressed in both oocytes and somatic cells, whereas the oocyte-type genes (20000 copies, tandemly arranged on several chromosomes) are only expressed during oogenesis and early embryogenesis when the larger amount of 5S rRNA is synthesized (Peterson et al., 1980). Both families encode a 120 nucleotides (nt) 5S rRNA with a five-nucleotide difference between the oocyte and somatic 5S rRNAs (Ford, 1973; Wolffe, 1994).

In the plant kingdom, results obtained in rice suggest a developmental control of the 5S rRNA genes expression. Two species of $5 S$ rRNA were recovered in $48 \mathrm{~h}$ germinated embryos whereas only one was present in ungerminated embryos (Hariharan et al., 1987). In Arabidopsis thaliana, different species of $5 \mathrm{~S}$ rRNA were recovered in tissues like seeds and roots, but this heterogeneity is absent in adult leaves and stems (Mathieu et al., 2003a) implying silencing of the corresponding genes.

For several years our work has focused on the transcriptional regulation of $5 S$ rDNA in A. thaliana. This review demonstrates that $5 \mathrm{~S}$ rDNA is highly regulated at different levels and that epigenetic mechanisms are involved in both $A$. thaliana and X. laevis.

\section{Arabidopsis 5S rDNA loci}

A. thaliana has approximately thousands of $5 S$ rRNA genes per haploid genome and these occur in tandem arrays (Campell et al., 1992), localized in the pericentromeric heterochromatin of chromosomes 3, 4 and 5 in the Columbia ecotype (with a large locus on the left arm and a small locus on the right arm of chromosome 5) 
(Murata et al., 1997; Fransz et al., 1998; Tutois et al., 1999; Cloix et al., 2000). A typical $5 S$ rDNA unit is $0.5 \mathrm{~kb}$ long (Figure 1). It contains a $120 \mathrm{bp}$ transcribed sequence, with an internal promoter and an approximately $380 \mathrm{bp}$ intergenic spacer. The latter contains a TATA-like motif $28 \mathrm{bp}$ upstream the transcribed region, necessary for transcription, and a simple cluster of $\mathrm{T}$ residues downstream the transcribed region, used as terminator signal (Cloix et al., 2003). Transcription by RNA polymerase III gives rise to a $120 \mathrm{nt} 5 \mathrm{~S}$ rRNA (Cloix et al., 2002).

\section{In $A$. thaliana, only two $5 S$ rDNA arrays are transcribed}

Our in vivo and in vitro results have revealed that $5 S$ rRNA genes from chromosome 3 and from the small locus of chromosome 5 are not expressed (Figure 2). The presence of numerous mutations in the internal promoter of these genes probably prevents their transcription (Cloix et al., 2003). 5S rRNA genes from chromosome 3 are dispensable since some ecotypes lack these loci without deleterious effects for the plant (Fransz et al., 1998; Tutois et al., 2002).

In vivo and in vitro experiments have shown that only two 5S rDNA loci are transcribed in the cell: the locus on chromosome 4 and the large locus on the left arm of chromosome 5 (Figure 2; Cloix et al., 2002, 2003). These two $5 S$ blocks are around $150 \mathrm{~kb}$, each containing around 300 tandemly repeated 5S rDNA units.

\section{S rRNA genes and 5S rRNA heterogeneity}

In Arabidopsis, we identified two types of $5 S$ rRNA genes in each of the two transcribed 5S loci (chromosome 4 and large locus on the left arm of chromosome 5). The first class corresponds to the major genes (which represent $15-20 \%$ of the potentially transcribed $5 S$ genes) coding for one 5S rRNA species, whereas the second class contains what we have named the minor 5S rRNA genes $(80-85 \%$ of the potentially transcribed $5 S$ genes; Figure 2). These latter genes harbor one to three nucleotide substitutions in their transcribed region compared to the major genes (Cloix et al., 2002). We observed that only the major 5S rRNA genes are transcribed in wild-type (WT) 3-week-old leaves (Mathieu et al., 2003a). Since in vitro experiments have demonstrated that minor genes have the potential to be transcribed, their silent state must result from an active process. This indicates that inside the two transcribed $5 S$ blocks, only a fraction of the 5S rRNA genes are transcribed (the major genes) with therefore a silencing of the rest of the genes (the minor genes) in WT leaf nuclei.

In the Xenopus model, 5S gene heterogeneity results from the presence of two distinct, physically separated, $5 S$ gene families: the constitutively expressed somatic one and the oocyte one whose expression is restricted to oogenesis. They encode a 120 nt $5 S$ rRNA with a fivenucleotide difference (Ford, 1973).

When the greatest quantities of $5 S$ rRNA are accumulated, that is in the seed and during oogenesis, in Arabidopsis and Xenopus respectively, 5S rRNA heterogeneity is observed. The $5 \mathrm{~S}$ rRNA heterogeneity depends on tissues and/or developmental stages and implies mechanisms which dictate the on and off states of the corresponding $5 \mathrm{~S}$ genes.

\section{Methylation of $5 S$ rRNA genes}

DNA methylation is one of the major events causing gene repression. In plants, 5-25\% of all cytosines are methylated (Rangwala and Richards, 2004).

The tandemly repeated 5S rDNA has been shown to be highly methylated in different plant species: maize (Mascia et al., 1981), wheat (Grellet and Penon, 1984), lupin (Rafalski et al., 1982), pea (Ellis et al., 1988), flax (Goldsbrough et al., 1982) and tobacco (Fulnecek et al., 1998). Using genomic sequencing, we studied the methylation of $A$. thaliana $5 \mathrm{~S}$ rDNA and found it to be highly methylated (79\% of methylated cytosines) at CpG,

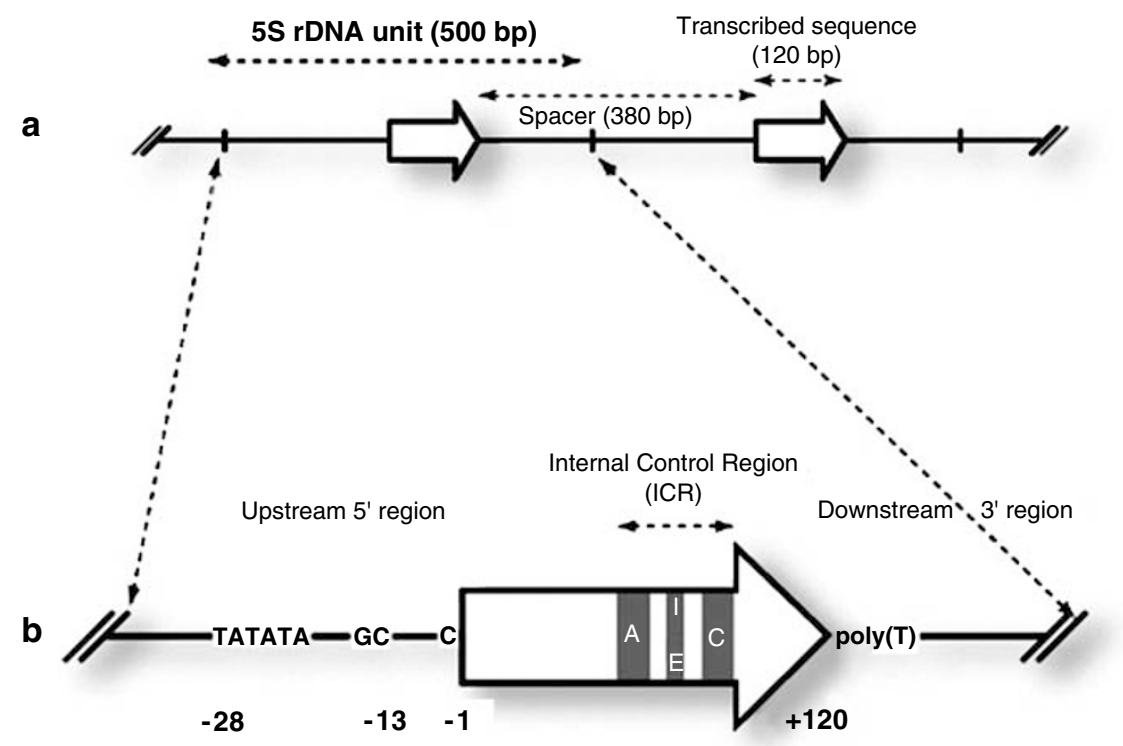

Figure 1 Structure of $A$. thaliana $5 S$ rDNA units. (a) Two tandemly organized $5 S$ rDNA units. (b) One $5 S$ rDNA unit with the 120 bptranscribed sequence containing the internal promoter composed of box A (A), intermediate element (IE) and box C (C). The upstream region contains three motifs necessary for transcription at $-28,-13$ and -1 . The downstream region contains the poly-T cluster used as transcription terminator. 

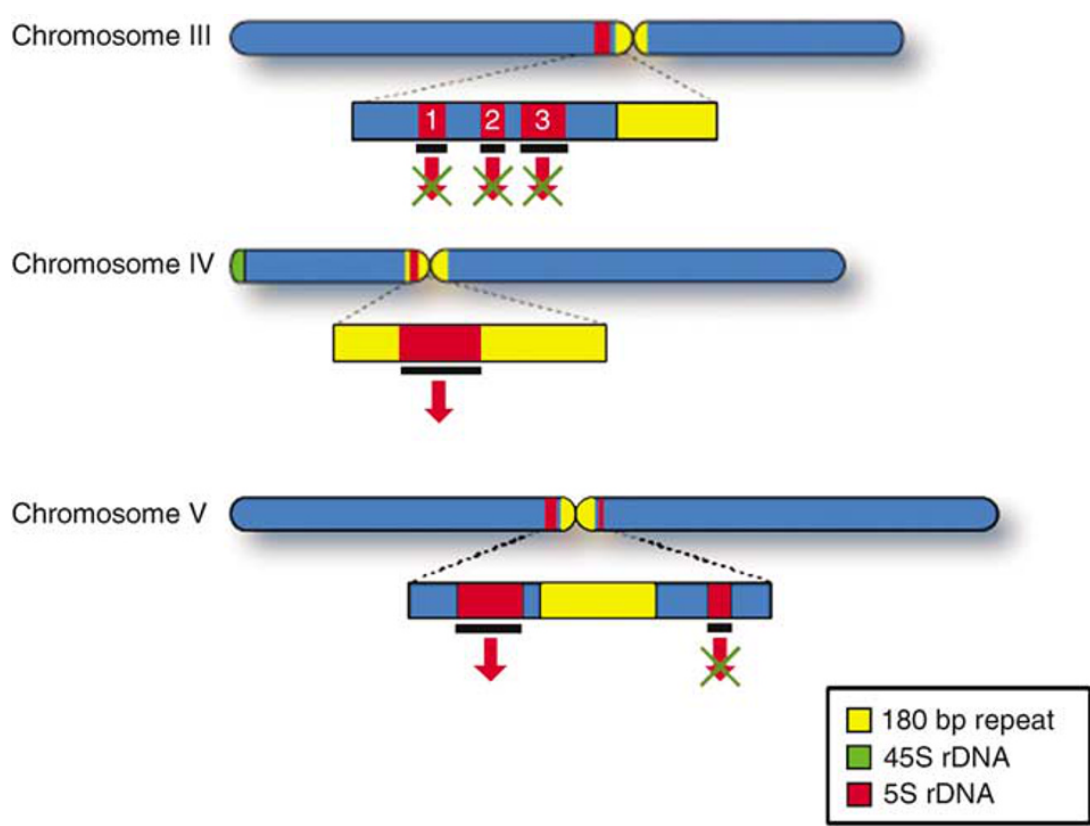

Figure 2 Localization of transcribed and not transcribed 5S rDNA loci. 5S loci (red) are localized in the pericentromeric region (enlarged on the figure) of chromosomes 3,4 and 5 composed of the 180 bp-satellite (yellow) and other sequences (blue). The loci 1, 2, 3 of chromosome 3 and the small locus of chromosome 5 are not transcribed (crossed arrow). The $5 \mathrm{~S}$ locus of chromosome 4 and the large locus of chromosome 5 are the only transcribed loci (red arrow). Both contain major and minor $5 S$ genes, which have the ability to be transcribed.

CpNpG and asymmetrical contexts. We also identified a small fraction of less methylated 5S rDNA units (Mathieu et al., 2002), thought to be the transcribed fraction (see later). However, we did not find any nonmethylated $5 \mathrm{~S}$ genes, suggesting that all $5 \mathrm{~S}$ genes contain methylated cytosines, probably at degrees depending on their transcriptional activity. We found an inverse correlation between 5S rDNA methylation, studied with methylation-sensitive enzymes, and the proportion of minor 5S rRNA. Minor 5S rRNAs were recovered in roots $(13 \%)$, in plants treated with the cytosine methylation inhibitor compound 5-azacytidine $(22.7 \%)$ and in $d d m 1$ mutant plants (22\%, see later), where 5S rDNA is hypomethylated (Mathieu et al., 2003a).

DNA methylation is a stable epigenetic mark for transcriptional gene silencing (TGS). Miller et al. (1978) reported that Xenopus oocyte-type $5 \mathrm{~S}$ rDNA is highly methylated in erythrocytes where it is repressed, although no direct correlation between methylation and transcription has been made. To assess whether methylation impaired transcription, the expression of an in vitro methylated 5S gene was checked after injection into Xenopus oocytes. However, the absence of transcription inhibition (Besser et al., 1990) probably revealed that methylation alone was not sufficient to repress transcription, rather than an absence of influence of the methylation on Xenopus 5S rDNA transcription. According to Santoro and Grummt (2001), no transcription repression was observed presumably because the DNA was not properly packaged into nucleosomes. Similarly, in vitro transcription of an Arabidopsis naked 5S rDNA gene or mouse 45S rDNA gene was not impaired by DNA methylation (Santoro and Grummt, 2001; Mathieu et al., 2002). This suggests the requirement for a specific chromatin state for the repression of these genes in the cell.

The RNAi pathway is proposed to be involved in the silencing of $5 S$ rRNA genes in Arabidopsis

Like almost every eukaryote, plants have the potential to neutralize invading nucleic acids and to repress repetitive sequences to prevent deleterious effects on genome stability and expression. These sequences can be repressed transcriptionally (TGS) through DNA methylation, histone methylation and/or chromatin remodeling. Short interfering RNAs (siRNAs) of 21-24 nt, processed from double-stranded RNAs (dsRNAs) derived from the controlled sequences, have a key role in determining the mode and sequence specificity.

In $A$. thaliana, silencing at endogenous repeat loci involves histone $\mathrm{H} 3$ lysine 9 (H3K9) methylation and RNA-directed DNA methylation (RdDM) (Pelissier et al. 1999; Mathieu and Bender, 2004). RdDM is accomplished by the de novo cytosine methyltransferase domains rearranged methylase 2 (DRM2) (Cao et al., 2003) and defective in RNA-directed methylation 1 (DRD1) (Kanno et al., 2004), a SWI2/SNF2-related protein. RdDM is correlated with the production of homologous siRNAs. 5 S siRNAs are detected in WT plants (Xie et al., 2004) and $5 \mathrm{~S}$ rDNA is highly methylated at CNN (Mathieu et al., 2002), which is a hallmark of RdDM.

Recent works have proposed the following model for the maintenance of the heterochromatic state at Arabidopsis pericentromeric sequences such as AtSN1 (small retroelements), $45 S$ and $5 S$ rDNA: transcripts trailing from polymerases (I or III in these cases) that are stalled or slowed by DRM-mediated de novo methylation are sensed as aberrant and directly or indirectly become 
templates for RNA polymerase IVa (Pol IVa), one of the two forms of the plant-specific nuclear RNA polymerase IV (Pol IV) (Herr et al., 2005; Kanno et al., 2005; Onodera et al., 2005; Pontier et al., 2005; Vaucheret, 2005). Pol IVa would generate precursor RNA at the endogenous repeats and these transcripts then move to the nucleolus where their complements are generated by RNA-dependent RNA polymerase 2 (RDR2) transcription. The resulting double-stranded RNA are then diced by dicer-like 3 (DCL3) and loaded into an argonaute 4 (AGO4)-containing effector complex or RNA-induced silencing complex (RISC) within the siRNA processing centers in the nucleolus. Then a subunit of the second Pol IV form, Pol IVb, would associate with AGO4-RISC (Pontes et al., 2006).

How AGO4-RISC-Pol IVb complexes mediate their effect on chromatin modification at target loci is unclear. The resulting compacted chromatin is methylated at DNA, methylated and deacetylated at histones. De novo DNA methylation by DRM2, which is predicted to contribute to aberrant RNA production, would provide for positive feedback (Pontes et al., 2006). Although this model is highly probable (5S siRNA accumulation is decreased in pol $I V, r d r 2, d c l 3$ mutants), it needs to be checked for 5S rDNA transcription level (derepression of minor genes in RNAi pathway mutants). In addition, if RNAi mediates silencing, the initiating trigger RNA needs to be identified. Recently, Mayer et al. (2006) reported that long intergenic spacer transcripts, which are processed into smaller intermediate RNAs, are required for heterochromatin and silencing of a subset of mouse $45 \mathrm{~S}$ rDNA arrays. Whether such transcripts have similar function for 5S rDNA needs to be investigated.

Finally, it is reasonable to assume that the $21-24$ nt 5S siRNAs cannot discriminate the major and minor $5 S$ rRNA genes. However, we postulate the existence of a chromatin condensation gradient along the $5 \mathrm{~S}$ rDNA arrays. It remains to be found whether some structural features of the loci can favor this model and explain the selective repression of the minor $5 \mathrm{~S}$ rRNA genes.

\section{Involvement of the chromatin structure}

Both in vitro transcription experiments (Mathieu et al., 2002) and the Pol IV model (Onodera et al., 2005; Pontes et al., 2006) suggest the involvement of the chromatin structure in $5 S$ rDNA regulation.
In Arabidopsis, the involvement of chromatin structure in the transcriptional regulation of $5 S$ genes was demonstrated by cytological experiments using the $d d m 1$ mutant. The decrease in DNA methylation 1 gene (DDM1) encodes a SWI/SNF2-like chromatin remodeling protein (Jeddeloh et al., 1999; Brzeski and Jerzmanowski, 2003). The $d d m 1$ mutation is known to cause a substantial demethylation of the genome and a striking decondensation of the chromocenters (Soppe et al., 2002). In leaf nuclei of 3-week-old WT plants, fluorescent in situ hybridization (FISH) with a $5 S$ rDNA probe revealed that a fraction of $5 \mathrm{~S}$ rDNA forms loops that emanate from the chromocenters (Figure 3). In this tissue, only the major 5S rRNA was recovered and the transcribed major $5 S$ genes presumably reside in the $5 S$ loops. The $5 S$ rDNA fraction residing in the heterochromatic chromocenters is considered to be silent. In the $d d m 1$ mutant, larger $5 S$ rDNA loops were observed and some $5 S$ minor genes were expressed with $22 \%$ minor $5 S$ rRNA transcripts recovered in 3-week-old leaves (minor 5S rRNAs contain 1-2 nucleotide substitutions compared to the major $5 S$ rRNAs; Mathieu et al., 2003a).

In Xenopus, the involvement of chromatin structure was shown by the appearance of the linker histone $\mathrm{H} 1$ in embryonic chromatin, which correlates with the establishment of repression of oocyte-type $5 S$ genes. Histone $\mathrm{H} 1$ is available during embryogenesis but not during oogenesis where it is replaced by the B4 variant. Histone H1 may direct the correct positioning of nucleosomes over the oocyte promoter (Chipev and Wolffe, 1992), which suggests significant phasing of nucleosomes influencing transcription factor IIIA (TFIIIA) binding over the promoters (Gottesfeld and Bloomer, 1980; Hayes and Clemens, 1992; Lee et al., 1993; Yang and Hayes, 2003). Changes in chromatin composition, as embryogenesis proceeds, resulting in a compacted chromatin in the presence of histone $\mathrm{H} 1$ and leading to the final repression of the oocyte $5 S$ rRNA genes, had a major role in differential gene activity between the two $5 S$ gene families (Wolffe, 1989; Dimitrov et al., 1993; Bouvet et al., 1994; Sera and Wolffe, 1998). It is likely, in plants, that chromatin condensation might be influenced by the position of nucleosomes along the DNA fiber (MartinezBalbas et al., 1990). In tobacco, 5S rDNA units can be wrapped in a number of alternative nucleosome frames; thus potentially varying accessibility of transcription factors across the 5S rDNA tandem array (Fulnecek et al., 2006).
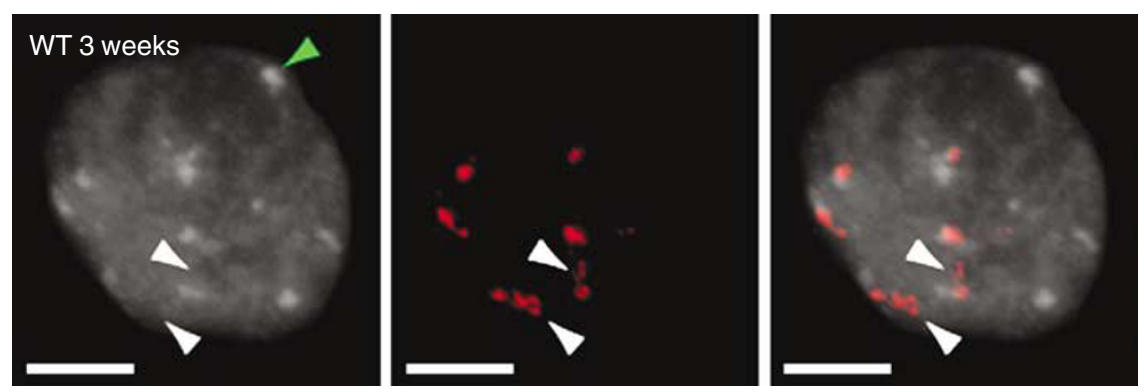

Figure $35 \mathrm{~S}$ rDNA loops emanate from chromocenters in nuclei of 3-week-old plants. The heterochromatic chromocenters are DAPI-stained structures (green arrow). FISH with a $5 \mathrm{~S}$ rDNA probe (red signal) on 3-week-old nuclei from WT plants. Bar $=5 \mu \mathrm{m}$. A fraction of the $5 \mathrm{~S}$ rDNA signal is located in the heterochromatic chromocenters, while the other fraction forms loops within euchromatin (white arrows). Counterstaining with DAPI (left), FISH with the $5 \mathrm{~S}$ rDNA probe (middle), and the merge of both (right) are shown. 


\section{$5 \mathrm{~S}$ rDNA histone modifications}

The combination of DNA and histone modifications (methylation, acetylation, etc.) specifies chromatin structure and determines its transcriptional competence (Jenuwein and Allis, 2001). Transcribed and silent 5S rDNA fractions are therefore expected to contain different histone modifications specific for active and inactive transcriptional states, respectively.

Acetylation of the N-terminal domain of histones weakens the interaction of histones with DNA and facilitates the recognition of binding sites by transcription factors. In Xenopus, in vitro experiments from Tse et al. (1998) showed that high levels of acetylation completely inhibited higher order folding of 12-mer nucleosomal arrays assembled onto a DNA template consisting of twelve 5S tandem repeats. This was correlated with a large enhancement in the ability of RNA polymerase III to transcribe through the 12-mer nucleosomal arrays. Chromatin immunoprecipitation (ChIP) experiments conducted by Howe et al. (1998) confirmed that the upstream, non-transcribed region of the transcriptionally active Xenopus-somatic $5 \mathrm{~S}$ genes is packaged with acetylated histone $\mathrm{H} 4$, whereas repressed oocyte $5 S$ genes were not.

As already mentioned, silencing at endogenous repeat loci in A. thaliana involves RdDM and histone modifications. Lysines of histones $\mathrm{H} 3$ and $\mathrm{H} 4$ can appear in mono-, di- and trimethylated states (Paik and Kim, 1971; Turner, 2005), which have been recently proposed to reflect functional differences (Dutnall, 2003). In general, methylation of histone $\mathrm{H} 3$ lysine 4 has been associated with transcriptionally active genes (Sims et al., 2003). Conversely, methylation of $\mathrm{H} 3 \mathrm{~K} 9$ has been linked to heterochromatin and gene silencing (Lippman and Martienssen, 2004). Immunocytology has shown that Arabidopsis 5S loops, expected to contain the transcribed fraction, have euchromatic features such as dimethylation of lysine 4 of histone $\mathrm{H} 3$ (H3K4me2) and acetylation of lysine 9 of histone H3 (H3K9Ac), compared to the heterochromatic status (5-methylcytosine and H3K9me2) of the silenced 5S rDNA units colocalizing with the chromocenters (Mathieu et al., 2003a). ChIP experiments have shown that $5 \mathrm{~S}$ rRNA genes become enriched in the euchromatic marks H3K4me2 and trimethylation of lysine 27 of histone $\mathrm{H} 3$ (H3K27me3) in $d d m 1$, resulting from loss of $\mathrm{CpG}$ methylation and correlating with the release of silencing of some minor $5 S$ rRNA genes and the larger 5S loops (Mathieu et al., 2003a, 2005) (Table 1).

ChIP experiments revealed that $5 \mathrm{~S}$ rDNA is also associated with the heterochromatic marks H3K27me1 (monomethylation) and H3K27me2. However these 5S rDNA methylation patterns were both unaffected by CG hypomethylation in $d d m 1$ and met1 (CG maintenance DNA methyltransferase) mutants, demonstrating their independence of CG methylation (Mathieu et al., 2005).

Table 1 Histone modifications at $A$. thaliana $5 S$ rDNA

\begin{tabular}{ll}
\hline Euchromatin & Heterochromatin $^{2}$ \\
\hline H3K4me2 & H3K9me2 \\
H3K27me3 & H3K27me1 ${ }^{\text {b }}$ \\
H3K9Ac & H3K27me2
\end{tabular}

CG methylation directly restrains H3K27me3 (Mathieu et al., 2005).

${ }^{a}$ CG methylation-dependent (Tariq et al., 2003).

${ }^{\mathrm{b}} \mathrm{CG}$ methylation-independent (Mathieu et al., 2005).
The silenced 5S rDNA fraction is expected to be preferentially associated with these modifications.

Histone methylation depends on histone methyltransferases and the Arabidopsis genome encodes nine H3K9 methyltransferases (Baumbusch et al., 2001), referred as SuvH proteins. Chromomethylase3 (CMT3)-mediated non-CG maintenance methylation (see later) depends on H3K9 methylation. Ebbs and Bender (2006) have shown that the SuvH proteins 4, 5 and 6 make different relative contributions to the maintenance of $\mathrm{H} 3 \mathrm{~K} 9$ and DNA methylation at different loci, suggesting locusspecific mechanisms for their recruitment or activation. At 5S repeats, SuvH4/kryptonite, SuvH5 and SuvH6 together control CMT3-mediated DNA methylation with the hierarchy SuvH4 $>$ SuvH5 and SuvH5 = SuvH6. They are therefore believed to methylate histones $\mathrm{H} 3$ at $5 \mathrm{~S}$ rDNA, although histone methylation patterns have not been studied in the mutants.

Proteins considered to be involved in epigenetic pathways acting on 5S rDNA are presented in Table 2 . In most of the cases, the impact of the proteins has been tested through the analysis of $5 \mathrm{~S}$ rDNA methylation or accumulation of $5 \mathrm{~S}$ siRNAs in the corresponding mutants. In some of them, we have also studied the impact of the mutation on 5S rDNA transcription. This is an accurate way to show the impact of a protein when DNA methylation and siRNA accumulation are unaffected in the corresponding mutant.

\section{A new 5S-210 transcript arises from 5S rDNA CG-hypomethylation}

In plants, DNA methylation patterns at CG sites are maintained by methyltransferase 1 (MET1), while CMT3 is the major methyltransferase that maintains non-CG methylation at transposable elements and centromeric repeats (Finnegan and Kovac, 2000; Bartee et al., 2001; Lindroth et al., 2001; Tompa et al., 2002; Lippman et al., 2003; Tran et al., 2005). We have investigated 5S rRNA gene silencing in mutants of MET1 and CMT3. The release of $5 \mathrm{~S}$ gene silencing was tested through the detection of 210 nt-long 5S transcripts (named 5S-210). This extends beyond the $120 \mathrm{bp}$-transcribed sequence and contains part of the spacer, up to now considered as nontranscribed. The sequencing of 5S-210 transcripts revealed that they only originate from the transcriptionally active $5 S$ repeat clusters (chromosome 4 and large locus on chromosome 5). 5S-210 is observed in met1 but not in the cmt3 mutant, indicating that it is mainly under the control of MET1-mediated CG methylation whereas non-CG methylation has little or no influence (Table 2; Vaillant et al., 2006). We actually do not know the function of this transcript and whether the 5S siRNAs derive from this longer transcript.

Surprisingly, combination of met 1 and cmt3 mutations in the double-mutant releases $5 \mathrm{~S}$ gene silencing (at 5S210) to a lesser extent than the met1 mutation alone, although 5S rDNA methylation was strongly reduced at both CGs and non-CGs (Vaillant et al., 2006). This result points to the existence of additional regulatory pathways acting on $5 \mathrm{~S}$ rDNA transcription.

5S rDNA is a target of the methylation-independent MOM pathway

Previous studies have identified Morpheus' molecule 1 (MOM1) as a component of a silencing mechanism 
Table 2 Mutants of epigenetic pathways acting on 5 S rDNA methylation, accumulation of $5 S$ siRNAs or $5 S$ rDNA transcription

\begin{tabular}{|c|c|c|c|c|}
\hline Protein/function & $5 S$ rDNA methylation & $\begin{array}{l}\text { 5S siRNA } \\
\text { accumulation }\end{array}$ & $\begin{array}{l}\text { Minor } 5 S / 210-5 S \\
\text { rRNA }\end{array}$ & References \\
\hline Pol IVa (RNA polymerase IV) & Reduced at CG, CNG, CNN & Decreased & ND & $\begin{array}{l}\text { Onodera et al. (2005), } \\
\text { Pontes et al. (2006) }\end{array}$ \\
\hline $\begin{array}{l}\text { RDR2 (RNA-dependent RNA } \\
\text { polymerase) }\end{array}$ & Reduced at CG, CNG, CNN & Decreased & ND & $\begin{array}{l}\text { Xie et al. (2004), } \\
\text { Pontes et al. (2006) }\end{array}$ \\
\hline DCL3 (dicer-like) & Reduced at CG, CNG, CNN & Decreased & ND & $\begin{array}{l}\text { Xie et al. (2004), } \\
\text { Pontes et al. (2006) }\end{array}$ \\
\hline AGO4 (argonaute) & Reduced at CG, CNG & Decreased & ND & $\begin{array}{l}\text { Xie et al. (2004), } \\
\text { Zilberman et al. (2004), } \\
\text { Zilberman et al. (2003) }\end{array}$ \\
\hline Pol IVb (RNA polymerase IV) & Reduced at CG, CNG, CNN & Decreased & ND & $\begin{array}{l}\text { Onodera et al. (2005), } \\
\text { Pontes et al. (2006) }\end{array}$ \\
\hline $\begin{array}{l}\text { DRM2 (domains rearranged } \\
\text { methylase) }\end{array}$ & Reduced at CG, CNG, CNN & Decreased & ND & $\begin{array}{l}\text { Elmayan et al. (2005), } \\
\text { Zilberman et al. (2004), } \\
\text { Onodera et al. (2005) }\end{array}$ \\
\hline $\begin{array}{l}\text { SuvH 4, 5, } 6 \text { (histone H3K9 } \\
\text { methyltransferase) }\end{array}$ & Reduced at $\mathrm{CNG}$ & $\begin{array}{l}\text { Increased (1) } \\
\text { Unchanged (2) }\end{array}$ & ND & $\begin{array}{l}\text { Ebbs and Bender (2006), } \\
\text { (1) Elmayan et al. (2005), } \\
\text { (2) Zilberman et al. (2004) }\end{array}$ \\
\hline $\begin{array}{l}\text { MET1 (DNA } \\
\text { methyltransferase) }\end{array}$ & Reduced at CG, CNG & Increased $^{\mathrm{a}}$ & $5 S-210$ increased & $\begin{array}{l}\text { Onodera et al. (2005), } \\
\text { Vaillant et al. (2006), } \\
\text { Elmayan et al. (2005) }\end{array}$ \\
\hline $\begin{array}{l}\text { CMT3 } \\
\text { (chromomethyltransferase) }\end{array}$ & Reduced at CNG & Increased & 5S-210 unchanged & $\begin{array}{l}\text { Elmayan et al. (2005), } \\
\text { Vaillant et al. (2006) }\end{array}$ \\
\hline $\begin{array}{l}\text { DDM1 (chromatin } \\
\text { remodelling) }\end{array}$ & Reduced at CG, CNG & Increased $^{\mathrm{a}}$ & $\begin{array}{l}\text { 5S-210 increased, } \\
\text { minor 5S RNA } \\
\text { increased }\end{array}$ & $\begin{array}{l}\text { Mathieu et al. (2003a, b), } \\
\text { Vaillant et al. (2006) }\end{array}$ \\
\hline $\begin{array}{l}\text { HDA6/SIL1 (histone } \\
\text { deacetylase) }\end{array}$ & Reduced at CNG & Increased & ND & Elmayan et al. (2005) \\
\hline $\begin{array}{l}\text { MOM (chromatin } \\
\text { remodelling) }\end{array}$ & Unchanged & Unchanged & $\begin{array}{l}\text { 5S-210 increased, } \\
\text { minor 5S RNA } \\
\text { increase }\end{array}$ & $\begin{array}{l}\text { Onodera et al. (2005), } \\
\text { Vaillant et al. (2006), } \\
\text { Elmayan et al. (2005) }\end{array}$ \\
\hline
\end{tabular}

Abbreviation: ND, not determined.

a Derepression of 5S-repeat transcription results in the amplification of 5S siRNAs in these mutants.

independent of DNA methylation marks (Amedeo et al., 2000; Steimer et al., 2000; Mittelsten Scheid et al., 2002; Probst et al., 2003). They indicated that MOM1 is essential for silencing of heterochromatic genes and that the methylation-independent silencing MOM1 mechanism reinforces the methylation-based system and prevents extremely rapid epigenetic deregulation in plants with DNA methylation deficiencies (Mittelsten Scheid et al., 2002).

The MOM1 mutation releases silencing of transcriptionally silent information (TSI) repeats at chromocenters without altering their DNA methylation status (Steimer et al., 2000). The impact of mom 1 on $5 S$ gene silencing was tested and confirmed by the higher proportion of both minor and 5S-210 transcripts in mom1 than in WT plants, although the dense cytosine methylation of $5 S$ genes remained unaffected (Table 2). Nor were the heterochromatic-specific (H3K9me2, H3K27me2) and euchromaticspecific (H3K4me2, H3K27me3) histone H3 marks at $5 S$ rDNA modified in mom1 plants (Vaillant et al., 2006). Reverse transcription-polymerase chain reaction and RNA gel blot analyses revealed that the MOM1 transcript was slightly upregulated in cmt3 and met1 cmt3 but not in met1, suggesting that MOM1 transcription is influenced by non-CG methylation. Given that MOM1 participates in the control of $5 S$ gene silencing, we hypothesized that the upregulation of MOM1 in met1 cmt3 might counteract the release of silencing induced by met1 at $5 S$ genes. In contrast to the situation observed for $5 S$ genes, the TSI and the $180 \mathrm{bp}$ (two MOM1 targets) transcripts accumulate to higher levels in met $1 \mathrm{cmt3}$ than in either single mutant, indicating a synergistic effect of the mutations on release of silencing at these repeats and therefore a specific behavior of $5 \mathrm{~S}$ rRNA genes (Vaillant et al., 2006).

\section{Other forms of $A$. thaliana $5 S$ rDNA regulation}

These epigenetic mechanisms as well as other mechanisms participate in the control of $5 \mathrm{~S}$ rDNA transcription.

TFIIIA is a limiting factor for 5S rDNA transcription: TFIIIA is a 5S rDNA-specific transcription factor (Engelke et al., 1980). 5S rRNA, subsequently integrated in the large ribosomal subunit, needs to be produced in stoichiometric amounts with 45S rRNA. Our results revealed a good correlation between levels of AtTFIIIA mRNA and 5S rRNA (Mathieu et al., 2003b). TFIIIA could act as a limiting factor; for example, the transcription of additional minor $5 S$ genes in $d d m 1$ does not result in enhanced quantities of the $120 \mathrm{nt} 5 \mathrm{~S}$ rRNA. Therefore, TFIIIA seems to be an additional level of 5S rDNA transcriptional regulation (Mathieu et al., 2003a).

Facilitated recycling pathway for RNA polymerase III: The tRNA and 5S rDNA transcription complexes are known to be highly stable and can initiate multiple 
rounds of transcription (Sprague, 1995). In yeast, Dieci and Sentenac (1996) have shown that the terminator element appears to be required for polymerase III to enter the reinitiation pathway. Polymerase III preferentially recycles on the same template, in a way that allows it to complete new cycles more rapidly than the initial one. Accordingly, Jahn et al. (1987) provided some evidence that human Pol III is retained in the original transcription complex during the normal reinitiation process. Using in vitro transcription experiments, we (Cloix et al., 2003) and Yukawa et al. (2000) have shown that the $5^{\prime}$ TATA motif is important for reinitiation of respectively $5 S$ rRNA and tRNA genes both transcribed by the RNA polymerase III. Whether this is also the case in vivo is not yet known.

\section{Conclusion}

In conclusion, this review shows that $5 S$ rDNA is a subject of specific epigenetic regulations. The high conservation of the $5 S$ genes in terms of repetitivity, structure, DNA methylation, etc. suggests that epigenetic mechanisms are also involved in $5 \mathrm{~S}$ rDNA regulation in other organisms.

Numerous experiments remain to be done to characterize new regulating pathways acting on $5 S$ rDNA. The DNA repair pathway is one of them. Proteins acting in DNA repair pathway are required for maintenance of TGS at targets like Athila and TSI retrotransposons. The proteins BRU1, RPA2, FAS1 and 2 (chromatin-associated factors) do not affect DNA methylation, but bru1, fas1 and fas 2 mutants increased 5S siRNA accumulation suggesting they may participate in $5 \mathrm{~S}$ gene silencing (Elmayan et al., 2005). The finding that methyl-CpGbinding domain proteins (MBDs) associate with histone deacetylases in plants (Zemach and Grafi, 2003) suggests that MBDs may induce heterochromatin formation by coordinating the activities of histone deacetylases and histone methyltransferases. Experiments need to be carried out to show the binding of MBD proteins on 5S rDNA (at least the repressed heterochromatic fraction).

\section{Acknowledgements}

We thank C White for comments and English corrections. The laboratory acknowledges grant funding from the INCA (Institut National du Cancer, réseau Epipro), and from the Ministère de l'Enseignement supérieur et de la Recherche (ACI BCMS 045486).

\section{References}

Amedeo P, Habu Y, Afsar K, Mittelsten Scheid O, Paszkowski J (2000). Disruption of the plant gene MOM releases transcriptional silencing of methylated genes. Nature 405: 203-206.

Bartee L, Malagnac F, Bender J (2001). Arabidopsis cmt3 chromomethylase mutations block non-CG methylation and silencing of an endogenous gene. Genes Dev 15: 1753-1758.

Baumbusch LO, Thorstensen T, Krauss V, Fischer A, Naumann $\mathrm{K}$, Assalkhou R et al. (2001). The Arabidopsis thaliana genome contains at least 29 active genes encoding SET domain proteins that can be assigned to four evolutionarily conserved classes. Nucleic Acids Res 29: 4319-4333.

Besser D, Gotz F, Schulze-Forster K, Wagner H, Kroger H, Simon D (1990). DNA methylation inhibits transcription by
RNA polymerase III of a tRNA gene, but not of a $5 S$ rRNA gene. FEBS Lett 269: 358-362.

Bouvet P, Dimitrov S, Wolffe AP (1994). Specific regulation of Xenopus chromosomal 5S rRNA gene transcription in vivo by histone H1. Genes Dev 8: 1147-1159.

Brzeski J, Jerzmanowski A (2003). Deficient in DNA methylation 1 (DDM1) defines a novel family of chromatin-remodeling factors. J Biol Chem 278: 823-828.

Campell BR, Song Y, Posch TE, Cullis CA, Town CD (1992). Sequence and organization of $5 S$ ribosomal RNA-encoding genes of Arabidopsis thaliana. Gene 112: 225-228.

Cao X, Aufsatz W, Zilberman D, Mette MF, Huang MS, Matzke $\mathrm{M}$ et al. (2003). Role of the DRM and CMT3 methyltransferases in RNA-directed DNA methylation. Curr Biol 13: 2212-2217.

Chipev CC, Wolffe AP (1992). Chromosomal organization of Xenopus laevis oocyte and somatic 5S rRNA genes in vivo. Mol Cell Biol 12: 45-55.

Cloix C, Tutois S, Mathieu O, Cuvillier C, Espagnol MC, Picard $\mathrm{G}$ et al. (2000). Analysis of 5S rDNA arrays in Arabidopsis thaliana: physical mapping and chromosome-specific polymorphisms. Genome Res 10: 679-690.

Cloix C, Tutois S, Yukawa Y, Mathieu O, Cuvillier C, Espagnol MC et al. (2002). Analysis of the 5S RNA pool in Arabidopsis thaliana: RNAs are heterogeneous and only two of the genomic 5S loci produce mature 5S RNA. Genome Res 12: 132-144.

Cloix C, Yukawa Y, Tutois S, Sugiura M, Tourmente S (2003). In vitro analysis of the sequences required for transcription of the Arabidopsis thaliana 5S rRNA genes. Plant J 35: 251-261.

Dieci G, Sentenac A (1996). Facilitated recycling pathway for RNA polymerase III. Cell 84: 245-252.

Dimitrov S, Almouzni G, Dasso M, Wolffe AP (1993) Chromatin transitions during early Xenopus embryogenesis: changes in histone $\mathrm{H} 4$ acetylation and in linker histone type. Dev Biol 160: 214-227.

Ducrot C, Lefebvre O, Landrieux E, Guirouilh-Barbat J, Sentenac A, Acker J (2006). Reconstitution of the yeast RNA polymerase III transcription system with all recombinant factors. J Biol Chem 281: 11685-11692.

Dutnall RN (2003). Cracking the histone code: one, two, three methyls, you're out!. Mol Cell 12: 3-4.

Ebbs ML, Bender J (2006). Locus-specific control of DNA methylation by the Arabidopsis SUVH5 histone methyltransferase. Plant Cell 18: 1166-1176.

Ellis TH, Lee D, Thomas CM, Simpson PR, Cleary WG, Newman MA et al. (1988). 5S rRNA genes in Pisum: sequence, long range and chromosomal organization. Mol Gen Genet 214: 333-342.

Elmayan T, Proux F, Vaucheret H (2005). Arabidopsis RPA2: a genetic link among transcriptional gene silencing, DNA repair, and DNA replication. Curr Biol 15: 1919-1925.

Engelke DR, Ng SY, Shastry BS, Roeder RG (1980). Specific interaction of a purified transcription factor with an internal control region of 5S RNA genes. Cell 19: 717-728.

Finnegan EJ, Kovac KA (2000). Plant DNA methyltransferases. Plant Mol Biol 43: 189-201.

Ford SA (1973). Different sequences for 5S RNA in kidney cells and ovaries of Xenopus laevis. Nat New Biol 241: 7-12.

Fransz P, Armstrong S, Alonso-Blanco C, Fischer TC, TorresRuiz RA, Jones G (1998). Cytogenetics for the model system Arabidopsis thaliana. Plant J 13: 867-876.

Fulnecek J, Matyasek R, Kovarik A (2006). Plant 5S rDNA has multiple alternative nucleosome positions. Genome 49: 840-850.

Fulnecek J, Matyasek R, Kovarik A, Bezdek M (1998). Mapping of 5-methylcytosine residues in Nicotiana tabacum $5 \mathrm{~S}$ rRNA genes by genomic sequencing. Mol Gen Genet 259: 133-141.

Geiduschek EP, Kassavetis GA (2001). The RNA polymerase III transcription apparatus. J Mol Biol 310: 1-26. 
Goldsbrough PB, Ellis TH, Lomonossoff GP (1982). Sequence variation and methylation of the flax 5S RNA genes. Nucleic Acids Res 10: 4501-4514.

Gottesfeld JM, Bloomer LS (1980). Nonrandom alignment of nucleosomes on 5S RNA genes of X. laevis. Cell 21: 751-760.

Grellet F, Penon P (1984). Chromatin organization and methylation patterns of wheat 5S RNA genes. Plant Sci Lett 37: 129-136.

Hariharan N, Reddy PS, Padayatty JD (1987). 5S-rRNA genes in rice embryos. Plant Mol Biol 9: 443-451.

Hayes JJ, Clemens KR (1992). Locations of contacts between individual zinc fingers of Xenopus laevis transcription factor IIIA and the internal control region of a 5S RNA gene. Biochemistry 31: 11600-11605.

Herr AJ, Jensen MB, Dalmay T, Baulcombe DC (2005). RNA polymerase IV directs silencing of endogenous DNA. Science 308: 118-120.

Howe L, Ranalli TA, Allis CD, Ausio J (1998). Transcriptionally active Xenopus laevis somatic $5 \mathrm{~S}$ ribosomal RNA genes are packaged with hyperacetylated histone $\mathrm{H} 4$, whereas transcriptionally silent oocyte genes are not. J Biol Chem 273: 20693-20696.

Jahn D, Wingender E, Seifart KH (1987). Transcription complexes for various class III genes differ in parameters of formation and stability towards salt. J Mol Biol 193: 303-313.

Jeddeloh JA, Stokes TL, Richards EJ (1999). Maintenance of genomic methylation requires a SWI2/SNF2-like protein. Nat Genet 22: 94-97.

Jenuwein T, Allis CD (2001). Translating the histone code. Science 293: 1074-1080.

Kanno T, Huettel B, Mette MF, Aufsatz W, Jaligot E, Daxinger L et al. (2005). Atypical RNA polymerase subunits required for RNA-directed DNA methylation. Nat Genet 37: 761-765.

Kanno T, Mette MF, Kreil DP, Aufsatz W, Matzke M, Matzke AJ (2004). Involvement of putative SNF2 chromatin remodeling protein DRD1 in RNA-directed DNA methylation. Curr Biol 14: 801-805.

Lawrence RJ, Earley K, Pontes O, Silva M, Chen ZJ, Neves N et al. (2004). A concerted DNA methylation/histone methylation switch regulates rRNA gene dosage control and nucleolar dominance. Mol Cell 13: 599-609.

Lee DY, Hayes JJ, Pruss D, Wolffe AP (1993). A positive role for histone acetylation in transcription factor access to nucleosomal DNA. Cell 72: 73-84.

Lindroth AM, Cao X, Jackson JP, Zilberman D, McCallum CM, Henikoff $S$ et al. (2001). Requirement of CHROMOMETHYLASE3 for maintenance of CpXpG methylation. Science 292: 2077-2080.

Lippman Z, Martienssen R (2004). The role of RNA interference in heterochromatic silencing. Nature 431: 364-370.

Lippman Z, May B, Yordan C, Singer T, Martienssen R (2003). Distinct mechanisms determine transposon inheritance and methylation via small interfering RNA and histone modification. PLoS Biol 1: E67.

Martinez-Balbas A, Rodriguez-Campos A, Garcia-Ramirez M, Sainz J, Carrera P, Aymami J et al. (1990). Satellite DNAs contain sequences that induced curvature. Biochemistry 29: 2342-2348.

Mascia PN, Rubenstein I, Phillips RL, Wang AS, Xiang LZ (1981). Localization of the 5S rRNA genes and evidence for diversity in the 5S rDNA region of maize. Gene 15: 7-20.

Mathieu O, Bender J (2004). RNA-directed DNA methylation. J Cell Sci 117: 4881-4888.

Mathieu O, Jasencakova Z, Vaillant I, Gendrel AV, Colot V, Schubert I et al. (2003a). Changes in 5S rDNA chromatin organization and transcription during heterochromatin establishment in Arabidopsis. Plant Cell 15: 2929-2939.

Mathieu O, Probst AV, Paszkowski J (2005). Distinct regulation of histone $\mathrm{H} 3$ methylation at lysines 27 and 9 by $\mathrm{CpG}$ methylation in Arabidopsis. EMBO J 24: 2783-2791.
Mathieu O, Yukawa Y, Prieto JL, Vaillant I, Sugiura M, Tourmente S (2003b). Identification and characterization of transcription factor IIIA and ribosomal protein L5 from Arabidopsis thaliana. Nucleic Acids Res 31: 2424-2433.

Mathieu O, Yukawa Y, Sugiura M, Picard G, Tourmente S (2002). 5S rRNA genes expression is not inhibited by DNA methylation in Arabidopsis. Plant J 29: 313-323.

Mayer C, Schmitz KM, Li J, Grummt I, Santoro R (2006). Intergenic transcripts regulate the epigenetic state of rRNA genes. Mol Cell 22: 351-361.

Miller JR, Cartwright EM, Brownlee GG, Fedoroff NV, Brown DD (1978). The nucleotide sequence of oocyte 5S DNA in Xenopus laevis. II. The GC-rich region. Cell 13: 717-725.

Mittelsten Scheid O, Probst AV, Afsar K, Paszkowski J (2002). Two regulatory levels of transcriptional gene silencing in Arabidopsis. Proc Natl Acad Sci USA 99: 13659-13662.

Murata M, Heslop-Harrison JS, Motoyoshi F (1997). Physical mapping of the 5S ribosomal RNA genes in Arabidopsis thaliana by multi-color fluorescence in situ hybridization with cosmid clones. Plant J 12: 31-37.

Onodera Y, Haag JR, Ream T, Nunes PC, Pontes O, Pikaard CS (2005). Plant nuclear RNA polymerase IV mediates siRNA and DNA methylation-dependent heterochromatin formation. Cell 120: 613-622.

Paik WK, Kim S (1971). Protein methylation. Science 174: 114-119.

Pelissier T, Thalmeir S, Kempe D, Sanger HL, Wassenegger M (1999). Heavy de novo methylation at symmetrical and nonsymmetrical sites is a hallmark of RNA-directed DNA methylation. Nucleic Acids Res 27: 1625-1634.

Peterson RC, Doering JL, Brown DD (1980). Characterization of two xenopus somatic 5S DNAs and one minor oocytespecific 5S DNA. Cell 20: 131-141.

Pikaard CS (2000). The epigenetics of nucleolar dominance. Trends Genet 16: 495-500.

Pontes O, Li CF, Nunes PC, Haag J, Ream T, Vitins A et al. (2006). The Arabidopsis chromatin-modifying nuclear siRNA pathway involves a nucleolar RNA processing center. Cell 126: 79-92.

Pontier D, Yahubyan G, Vega D, Bulski A, Saez-Vasquez J, Hakimi MA et al. (2005). Reinforcement of silencing at transposons and highly repeated sequences requires the concerted action of two distinct RNA polymerases IV in Arabidopsis. Genes Dev 19: 2030-2040.

Probst AV, Fransz PF, Paszkowski J, Mittelsten Scheid O (2003). Two means of transcriptional reactivation within heterochromatin. Plant J 33: 743-749.

Rafalski JA, Wiewiorowski M, Soll D (1982). Organization and nucleotide sequence of nuclear 5S rRNA genes in yellow lupin (Lupinus luteus). Nucleic Acids Res 10: 7635-7642.

Rangwala SH, Richards EJ (2004). The value-added genome: building and maintaining genomic cytosine methylation landscapes. Curr Opin Genet Dev 14: 686-691.

Rogers SO, Bendich AJ (1987). Ribosomal RNA genes in plants: variability in copy number and in intergenic spacer. Plant Mol Biol 9: 509-520.

Santoro R, Grummt I (2001). Molecular mechanisms mediating methylation-dependent silencing of ribosomal gene transcription. Mol Cell 8: 719-725.

Sera T, Wolffe AP (1998). Role of histone H1 as an architectural determinant of chromatin structure and as a specific repressor of transcription on Xenopus oocyte 5S rRNA genes. Mol Cell Biol 18: 3668-3680.

Sims III RJ, Nishioka K, Reinberg D (2003). Histone lysine methylation: a signature for chromatin function. Trends Genet 19: 629-639.

Soppe WJ, Jasencakova Z, Houben A, Kakutani T, Meister A, Huang MS et al. (2002). DNA methylation controls histone H3 lysine 9 methylation and heterochromatin assembly in Arabidopsis. EMBO J 21: 6549-6559. 
Sprague KU (1995). Transcription of eukaryotic tRNA genes. In: Soll D, Rajbhandary UL (eds). tRNA: Structure, Biosynthesis and Function. American Society for Microbiology: Washington, DC. pp 31-50.

Steimer A, Amedeo P, Afsar K, Fransz P, Mittelsten Scheid O, Paszkowski J (2000). Endogenous targets of transcriptional gene silencing in Arabidopsis. Plant Cell 12: 1165-1178.

Tariq M, Saze H, Probst AV, Lichota J, Habu Y, Paszkowski J (2003). Erasure of CpG methylation in Arabidopsis alters patterns of histone $\mathrm{H} 3$ methylation in heterochromatin. Proc Natl Acad Sci USA 100: 8823-8827.

Tompa R, McCallum CM, Delrow J, Henikoff JG, van Steensel B, Henikoff S (2002). Genome-wide profiling of DNA methylation reveals transposon targets of CHROMOMETHYLASE3. Curr Biol 12: 65-68.

Tran RK, Henikoff JG, Zilberman D, Ditt RF, Jacobsen SE, Henikoff $S$ (2005). DNA methylation profiling identifies CG methylation clusters in Arabidopsis genes. Curr Biol 15: 154-159.

Tse C, Sera T, Wolffe AP, Hansen JC (1998). Disruption of higher-order folding by core histone acetylation dramatically enhances transcription of nucleosomal arrays by RNA polymerase III. Mol Cell Biol 18: 4629-4638.

Turner BM (2005). Reading signals on the nucleosome with a new nomenclature for modified histones. Nat Struct Mol Biol 408: 796-815.

Tutois S, Cloix C, Cuvillier C, Espagnol MC, Lafleuriel J, Picard G et al. (1999). Structural analysis and physical mapping of a pericentromeric region of chromosome 5 of Arabidopsis thaliana. Chromosome Res 7: 143-156.

Tutois S, Cloix C, Mathieu O, Cuvillier C, Tourmente S (2002). Analysis of $5 S$ rDNA loci among Arabidopsis ecotypes and subspecies. Genome Lett 1: 115-122.
Vaillant I, Schubert I, Tourmente S, Mathieu O (2006). MOM1 mediates DNA-methylation-independent silencing of repetitive sequences in Arabidopsis. EMBO Rep 7: 1273-1278.

Vaucheret H (2005). RNA polymerase IV and transcriptional silencing. Nat Genet 37: 659-660.

Wolffe AP (1989). Dominant and specific repression of Xenopus oocyte 5S RNA genes and satellite I DNA by histone H1. EMBO J 8: 527-537.

Wolffe AP (1994). The role of transcription factors, chromatin structure and DNA replication in 5 S RNA gene regulation. I Cell Sci 107: 2055-2063.

Xie Z, Johansen LK, Gustafson AM, Kasschau KD, Lellis AD Zilberman D et al. (2004). Genetic and functional diversification of small RNA pathways in plants. PLoS Biol 2: E104.

Yang Z, Hayes JJ (2003). Xenopus transcription factor IIIA and the $5 S$ nucleosome: development of a useful in vitro system. Biochem Cell Biol 81: 177-184.

Yukawa Y, Sugita M, Choisne N, Small I, Sugiura M (2000). The TATA motif, the CAA motif and the poly(T) transcription termination motif are all important for transcription reinitiation on plant tRNA genes. Plant I 22: 439-447.

Zemach A, Grafi G (2003). Characterization of Arabidopsis thaliana methyl-CpG-binding domain (MBD) proteins. Plant J 34: 565-572.

Zilberman D, Cao X, Jacobsen SE (2003). ARGONAUTE4 control of locus-specific siRNA accumulation and DNA and histone methylation. Science 299: 716-719.

Zilberman D, Cao X, Johansen LK, Xie Z, Carrington JC, Jacobsen SE (2004). Role of Arabidopsis ARGONAUTE4 in RNA-directed DNA methylation triggered by inverted repeats. Curr Biol 14: 1214-1220. 